\title{
BIODEGRADAÇÃO E ADESÃO PLAQUETÁRIA EM VASOS DE NANOCELULOSE BACTERIANA
}

\author{
V. H. SOUZA ${ }^{1}$, G. COLLA ${ }^{1}$, F. V. BERTI ${ }^{1}$ e L. M. PORTO ${ }^{1}$ \\ ${ }^{1}$ Universidade Federal de Santa Catarina, Departamento de Engenharia Química e Alimentos \\ E-mail para contato: vinicius_heidemann@intelab.com.br
}

\begin{abstract}
RESUMO - Os vasos de nanocelulose bacteriana (BNC) fazem parte de uma abordagem da área de engenharia tecidual que tenta gerar métodos paliativos para patologias cardiovasculares. Para a validação do uso de estruturas tubulares de BNC como substitutos de vasos sanguíneos faz-se necessária a avaliação da hemocompatibilidade do biomaterial utilizando-se testes como a biodegradação em plasma sanguíneo e a adesão plaquetária. Foram produzidos moldes de silicone para a produção de vasos de BNC nos formatos de vasos sanguineos saudáveis, vasos com arteriosclerose e vasos com aneurisma. Os vasos resultantes adquiriram os formatos desejados e a modelagem dos moldes de silicone pode proporcionar inúmeros tipos de alterações em suas estruturas permitindo assim que os vasos de BNC que mimetizem doenças como aneurisma e arteriosclerose possam ser usados como modelo de estudo dessas patologias. Os testes de biodegradação em plasma sanguíneo e adesão plaquetária indicaram que o material não degrada em plasma sanguíneo, mas que, ao entrar em contato com plaquetas, forma uma rede de fibrina que identifica o processo de coagulação sanguínea. Esta rede de fibrina forma-se em menor quantidade no lado denso do biomaterial e em maior quantidade no lado poroso, dessa forma caracteriza-se o biomaterial como potencialmente trombogênico.
\end{abstract}

\section{INTRODUÇÃO}

Devido à sua biocompatibilidade, custo relativamente baixo de produção, entre outras características, a BNC vem sendo amplamente utilizada e tornando-se grande alvo de estudos. Vasos feitos de BNC são de grande interesse médico, uma vez que seu uso estaria intrínseco a uma área recorrente de enfermidades do mundo contemporâneo: as doenças cardiovasculares (CASTRO et al., 2011). Os vasos de BNC fazem parte de uma abordagem da área de engenharia tecidual que tenta gerar métodos paliativos para esse tipo de patologias visando a sua aplicação como implantes, recobrimento de vasos sanguíneos in vivo, e modelos para diversos testes, como o treinamento de robôs cirurgiões. (COLLA, 2014)

Algumas doenças cardiovasculares estão relacionadas diretamente ao formato que os vasos sanguíneos podem vir a adquirir. Desta forma, faz-se necessário o estudo de estruturas que mimetizem vasos sanguíneos saudáveis e característicos de doenças cardiovasculares como a arteriosclerose e aneurisma, por exemplo. A arteriosclerose surge com a agressão ao endotélio vascular por fatores diversos, sendo um deles a elevação do LDL (low density 
lipoprotein) no sangue, essas lesões ocasionam o aumento da permeabilidade da camada íntima dos vasos e provocam à retenção de lipoproteínas plasmáticas, resultando em um estreitamento no diâmetro dos vasos (Boni et al., 2010). O aneurisma, em contrapartida, é quando acontece o aumento do diâmetro devido ao enfraquecimento da parede dos vasos. (Riambau et al., 2007)

No que concerne à validação do uso de estruturas tubulares de BNC como substitutos de pequenos vasos sanguíneos (diâmetro menor do que $6 \mathrm{~mm}$ ) e de baixa pressão, faz-se necessária a avaliação da hemocompatibilidade do material em questão. A hemocompatibilidade constitui-se de um ensaio experimental que considera uma série de parâmetros relacionados à compatibilidade do material quando em contato com sangue. Dois parâmetros importantes que geram uma resposta diretamente relacionada à hemocompatibilidade da BNC são os testes de biodegradação em plasma sanguíneo e avaliação da adesão plaquetária do biomaterial. (ASTM, 2000; Castro et al., 2011)

À vista do que aqui foi apresentado, o estudo propõe a produção de vasos de BNC com diferentes estruturas, simulando a arteriosclerose e aneurisma, e a avaliação da biodegradação em plasma sanguíneo e adesão plaquetária do biomaterial.

\section{METODOLOGIA}

\subsection{Produção dos vasos de BNC}

Para a produção dos vasos preparou-se anteriormente moldes de silicone com suportes de resina de acetato de polivinila (PVA), amido e plastificantes. Os suportes foram modelados nos formatos desejados e após o tempo de cura (24 h), preparou-se uma mistura para silicone, barrocha de silicone poli(dimetilsiloxano) (PDMS) com 3\% de catalisador (peróxido de dicumila). Preparou-se um pré-inóculo em um tubo cônico com $25 \mathrm{~mL}$ de meio manitol (25 $\mathrm{g} \cdot \mathrm{L}^{-1}$ de manitol, $5 \mathrm{~g} \cdot \mathrm{L}^{-1}$ de extrato de levedura e $3 \mathrm{~g} \cdot \mathrm{L}^{-1}$ de peptona bacteriológica) e aproximadamente 5 colônias da bactéria Gluconacetobacter hansenii por $\mathrm{mL}$ de meio. $\mathrm{O}$ compartimento usado para o crescimento da bactéria foi um aparato de vidro com duas conexões. Encaixou-se o molde de silicone nas aberturas internas do aparato e verteu-se o préinóculo. Adicionou-se $225 \mathrm{~mL}$ de meio manitol no aparato e foram conectadas mangueiras de silicone nas conexões externas do aparato, uma delas foi conectada à bomba de circulação de ar, com vazão próxima a 3,5 $\mathrm{L} \cdot \mathrm{min}^{-1}$. O crescimento bacteriano aconteceu em condição estática a temperatura ambiente durante 12 dias. Após os 12 dias de cultivo, os vasos foram purificados em solução $0,1 \mathrm{~mol} \cdot \mathrm{L}^{-1}$ de $\mathrm{NaOH}$ a $50{ }^{\circ} \mathrm{C}$ e após esse período o vaso foi lavado com água destilada até que $\mathrm{pH}$ da água de enxágue fosse equivalente ao da água usado na lavagem. Esterilizou-se o material em autoclave $\left(121^{\circ} \mathrm{C}\right.$ e $\left.1,1 \mathrm{~atm}\right)$.

\subsection{Biodegradação das membranas de BNC em plasma sanguíneo}

O estudo de biodegradação ocorreu num período de 6 semanas com o biomaterial cortado em formato de membranas que foram liofilizadas. O plasma rico em plaquetas (PRP) foi obtido previamente por centrifugação com sangue anticoagulado com citrato $3,2 \%$ a 2300 rpm. a $4{ }^{\circ} \mathrm{C}$ durante 4 minutos. O sangue utilizado para os testes foi coletado após a aprovação do comitê de ética de estudos em seres humanos - UFSC (CAAE 48296915.8.0000.0121) e os voluntários só doaram o sangue após lerem e assinarem o termo 
de consentimento livre e esclarecido. O sangue foi manipulado logo após a coleta em ambiente estéril, sem gerar biobanco.

Pesou-se as membranas de BNC liofilizadas. Distribuiu-se uma membrana por poço em placas de 24 poços. Adicionou-se $1 \mathrm{~mL}$ de PRP. As placas foram incubadas a $37^{\circ} \mathrm{C}$. Retirou-se 3 membranas nos períodos de 48 horas, 1, 2, 4 e 6 semanas. As membranas e o plasma contido nos respectivos poços foram armazenados em tubos cônicos de $2 \mathrm{~mL}$. A uma membrana no tempo de 6 semanas foi adicionado $1 \mathrm{~mL}$ de gluteraldeído $2,5 \%$ onde ficou sob repouso durante 10 minutos e depois foi desidratada com uma série de soluções alcoólicas. Liofilizou-se as membranas e, as membranas foram pesadas. A membrana tratada com o glutaraldeído $2,5 \%$ foi analisada por microscopia eletrônica de varredura (MEV). O plasma recolhido no decorrer do experimento foi analisado através de ensaio enzimático para determinação de glicose onde $10 \mu \mathrm{L}$ de plasma foram adicionados a $1000 \mu \mathrm{L}$ do reagente de cor (glicosidase, peroxidades e 4-aminoantipiridina) e após 10 minutos leu-se a absorbância a $505 \mathrm{~nm}$. O resultado foi comparado a um padrão de glicose nas mesmas condições do teste.

\subsection{Avaliação da adesão plaquetária das membranas de BNC}

O PRP utilizado foi obtido previamente por centrifugação do sangue anticoagulado com citrato $3,2 \%$ a $2300 \mathrm{rpm}$ a $4{ }^{\circ} \mathrm{C}$ durante 4 minutos. Em placas de 24 poços distribuiu-se uma membrana de BNC liofilizada por poço e lavou-se as membranas com tampão fosfato salino (PBS) por 5 vezes com um intervalo de 10 minutos entre cada lavagem. Retirou-se o PBS e adicionou-se o PRP previamente aquecido a $37^{\circ} \mathrm{C}$. Incubou-se as placas durante 30 minutos a $37^{\circ} \mathrm{C}$. Removeu-se cuidadosamente o PRP e lavou-se as membranas com PBS. Retirou-se o PBS e adicionou-se $1 \mathrm{~mL}$ de solução de gluteraldeído 2,5\% (v/v) onde ficou sob repouso durante 10 minutos. Desidratou-se em uma série de soluções alcoólicas. Liofilizou-se as membranas e as mesmas foram analisadas através de MEV. As micrografias geradas pela análise de MEV foram caracterizadas em comparação a uma escala desenvolvida por Cunha et al em 2014, essa escala, representada pela Figura 1, estabelece um índice semi-quantitativo para a padronização do parâmetro de trombogenicidade tendo como base os eventos celulares da cascata de coagulação.

Figura 1 - Escala dos índices de trombogenicidade

0

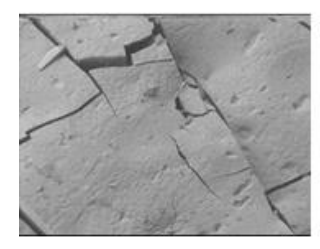

1

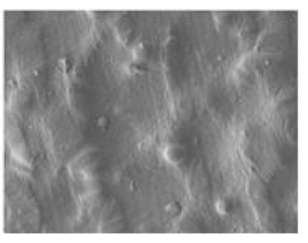

2

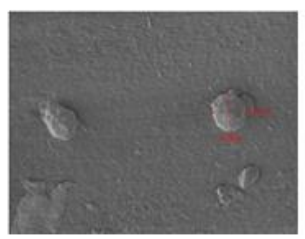

3

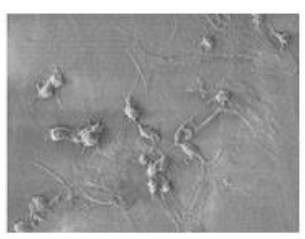

4

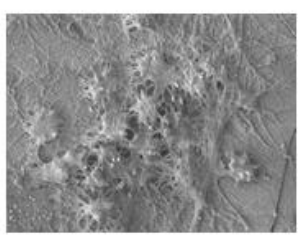

$\mathrm{Na}$ escala representada pela figura 1 cada índice representa níveis diferentes de coagulação gerada a partir do contato do material com sangue. Em índice 0 e 1 diz-se que o material não é trombogênico ou tem baixa trombogenicidade, em 2 tem-se um material com trombogenicidade média, em 3 e 4 atribui-se a condição de trombogênico. 


\section{RESULTADOS E DISCUSSÃO}

\subsection{Produção dos vasos de BNC}

Foram produzidos dois moldes com a resina de PVA, um foi modelado para simular um vaso com arteriosclerose e outro um vaso com aneurisma. Os moldes obtidos estão ilustrados na figura 2 (a). Produziu-se três vasos de BNC, que podem ser observados na figura 2 (b), um vaso com morfologia de vaso saudável e outros dois simulando arteriosclerose e aneurisma.

Figura 2 - (a) Ilustração dos molde de silicone; (b) Vasos de BNC produzidos.

\author{
Vaso \\ Saudável \\ Vaso com \\ Arteriosclerose \\ Vaso com \\ Aneurisma
}
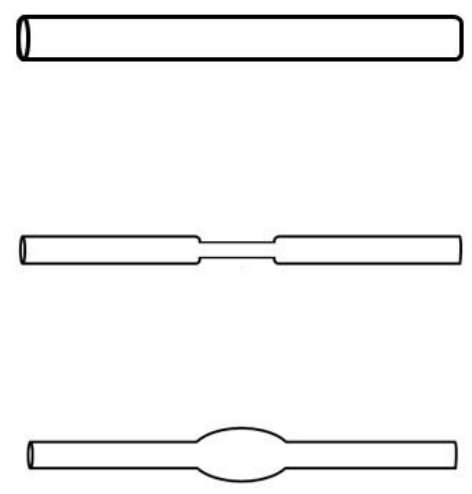

(a)
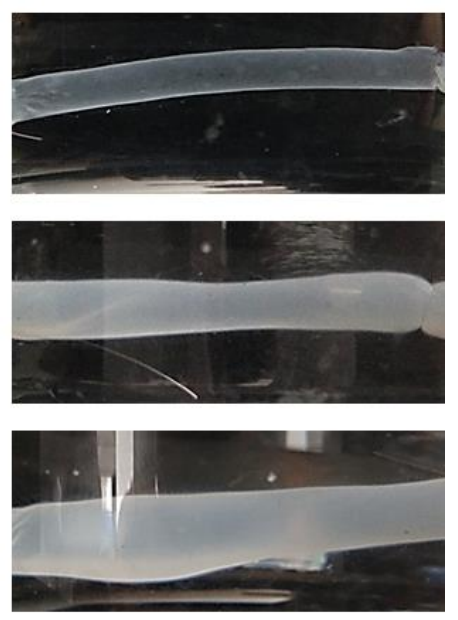

(b)

Os vasos produzidos adquiriram os formatos estabelecidos pelos moldes de silicone. Os diâmetros internos dos vasos ficaram na região de tamanho dos vasos de pequeno $(<6 \mathrm{~mm})$ e grande calibre (> 6mm) (Gartner\&Hiatt, 2007).

\subsection{Biodegradação das membranas de BNC em plasma sanguíneo}

O teste de biodegradação Figura 3 (a), que expressa tanto o resultado da análise da massa ao decorrer das semanas quanto a determinação da concentração de glicose no plasma. Analisando o gráfico temos que a massa das membranas aumentou no período observado (aproximadamente 500\%). Entretanto, pela análise de glicose não houve variação, estatisticamente significante, na concentração de glicose no plasma, apenas a concentração já encontrada no plasma antes do teste, indicando que não aconteceu degradação do material em plasma. A análise de MEV do último ponto do ensaio, Figura 3 (b), proporcionou uma diferente abordagem sobre o acréscimo de massa das membranas. Nota-se a formação de uma rede de fibrina sobrepondo as células aderidas, plaquetas e hemácias presentes no plasma. A formação dessa rede e a aderência das células à superfície do material inferem que, ao entrar em contato com o plasma, o material desencadeou a ativação das plaquetas (processo de coagulação sanguínea) e, consequentemente, a formação da rede de fibrina e a entrada das hemácias na estrutura tridimensional das membranas (Gorbet\& Michael, 2004). 
Figura 3 - Biodegradação da BNC em plasma sanguíneo humano: (a) Gráfico massa da BNC (•) e concentração de glicose ( $\bullet$ ) em função do tempo; (b) micrografia de MEV do último ponto (6 semanas) do ensaio de biodegradação

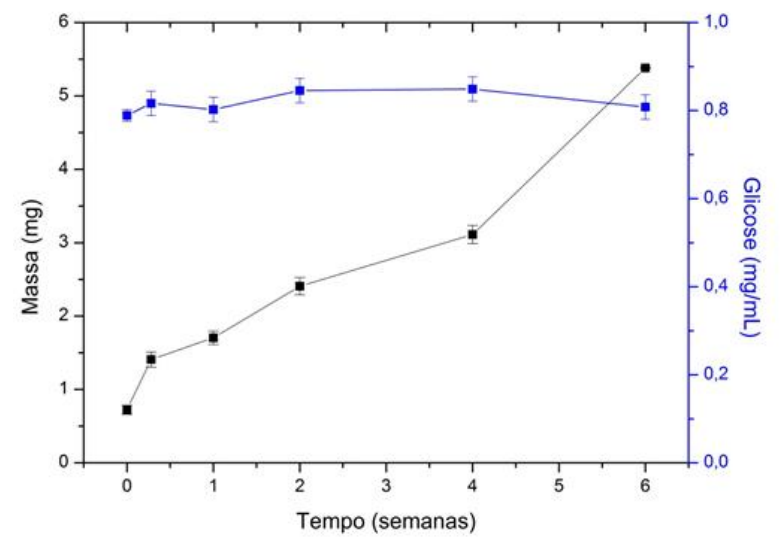

(a)

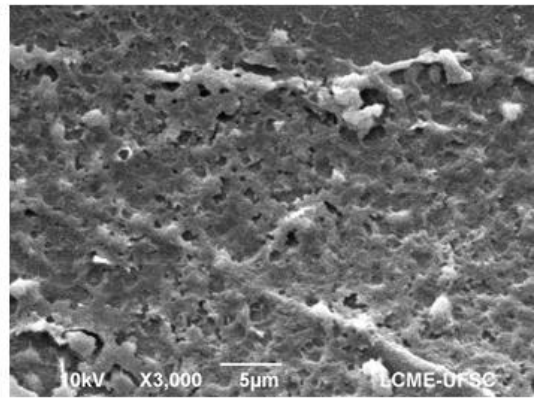

(b)

De qualquer forma, deve-se ressaltar que há a uma trombogenicidade inerente ao biomaterial indicada pela formação da rede de fibrina observada na micrografia.

\subsection{Avaliação da adesão plaquetária das membranas de BNC}

A adesão plaquetária foi analisada com o plasma em contato em duas diferentes situações: na camada densa e na camada porosa da membrana. Sabe-se que a parte interna do vaso, onde o material foi primeiramente gerado, é a parte densa, onde as fibras estão mais próximas com poros menores (Colla, 2014). Em contrapartida, a parte externa do vaso, é a parte porosa, onde a fibras são mais espaçadas entre si, os poros são maiores. A análise de MEV gerou micrografias (Figura 5) que passaram por uma seleção para sua representatividade e foram avaliadas conforme uma escala desenvolvida por Castro et al. 2014, onde divide-se a adesão plaquetária em índices.

Figura 5 - Análise da trombogenidade da BNC em plasma sanguíneo através do teste de adesão plaquetária. Micrografias de MEV dos lados denso e poroso da BNC
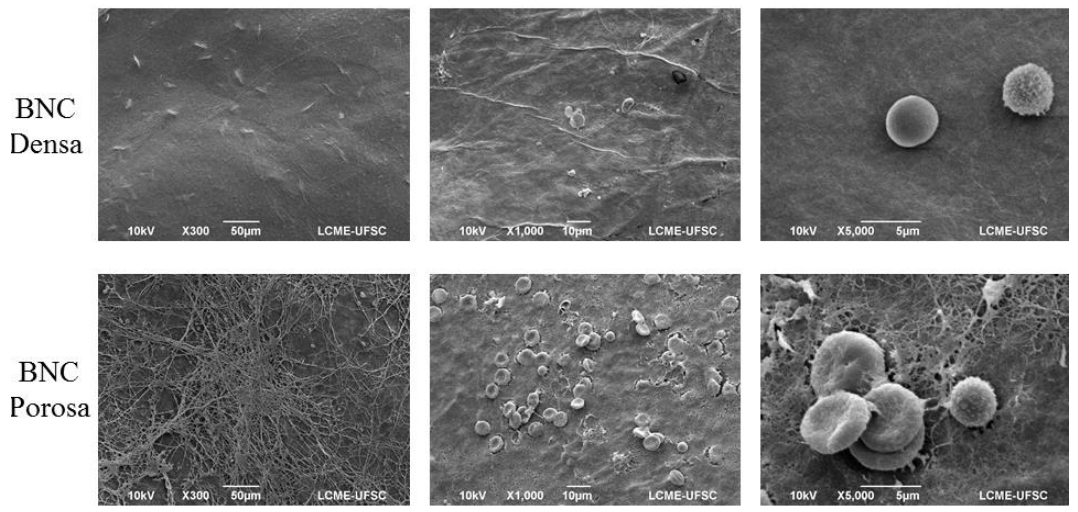

No lado denso da membrana notou-se a presença de plaquetas aderidas e isoladas, algumas com morfologia normal e outras já ativadas, apresentando uma maior rugosidade em sua membrana, como pode ser visto na imagem. A esse lado da membrana atribuiu-se índice 
2, indicando trombogenicidade média. Na superfície porosa da membrana ocorreu a formação de uma grande rede de fibrina, com a aderência de plaquetas ativadas e hemácias. A esse lado atribuiu-se índice 4, o que caracteriza o material como potencialmente trombogênico.

\section{CONCLUSÕES}

Os vasos de BNC produzidos a partir dos moldes de silicone adquiriram os formatos desejados de maneira que mimetizassem três situações diferentes: vaso saudável, vaso com arteriosclerose e vaso com aneurisma. As dimensões dos vasos podem ser facilmente manipuladas através da modelagem dos moldes de silicone, possibilitando que se produza vasos de diversos formatos, com inúmeras alterações em suas estruturas. $\mathrm{O}$ biomaterial se enquadrou como não degradável em plasma sanguíneo.

Os vasos de BNC foram caracterizados como potencialmente trombogênicos, sendo o lado poroso o que indicou um processo de coagulação mais avançado e o lado denso o que indicou apenas o início do processo de coagulação. Essa propriedade gera espaço para otimizações que podem ser feitas na superfície do biomaterial com a finalidade de melhorar sua compatibilidade com sangue.

\section{REFERÊNCIAS}

BONI, A.; PUGLIESE, C.; PATIN, R. V. Vitaminas antioxidantes e prevenção da arteriosclerose na infância, 28(4), 373-380, 2010.

CASTRO, C.; ZULUAGA, R.; PUTAUX, J.-L.; CARO, G.; MONDRAGON, I.; GAÑ́AN, P. Structural characterization of bacterial cellulose produced by Gluconacetobacter swingsii sp. from Colombian agroindustrial wastes. CarbohydratePolymers, v. 84, n. 1, p. 96-102, 2011.

COLLA, G.; PORTO, L. M. Development of artificial blood vessels through tissue engineering. BMC Proceedings. Vol. 8. No. 4. BioMed Central, 2014

CUNHA, T. F.; MANETTA, A. P.; SILVA, F. M.; SILVA, C. V.; HIGA, O. Z. Padronização do parâmetro de trombogenicidade utilizando índice semi-quantitativo baseado nos eventos celulares da cascata de coagulação. Congresso Latino Americano de órgãos artificiais e biomateriais - COLAOB , 2014.

GARTNER, L. P.; HIATT, J. L. Tratado de histologia em cores. Elsevier, 2007.

GORBET, Maud B.; MICHAEL V. Sefton. Biomaterial-associated thrombosis: roles of coagulation factors, complement, platelets and leukocytes. Biomaterials 25.26, 56815703, 2004.

RIAMBAU, V.; GUERRERO, F.; MONTAÑÁ, X.; GILABERT, R. Aneurisma de aorta abdominal y enfermedad vascular renal. Revista Española de Cardiología, 60(6), 639654, 2007. 